\title{
Supply chain sustainability performance measurement of small and medium sized enterprises using structural equation modeling
}

\author{
Chrisovalantis Malesios ${ }^{1}$ (D) Prasanta K. Dey ${ }^{1} \cdot$ Fuad Ben Abdelaziz $^{2}$
}

Published online: 24 October 2018

(c) The Author(s) 2018

\begin{abstract}
Sustainability of small and medium sized enterprises (SMEs) is significant as SMEs contribute to GDP substantially in every economy. This research develops an innovative sustainable supply chain performance measurement model for SMEs. Prior researches predominantly use balanced score card (BSC) approach that presume causal relationship of criteria and Data Envelopment Analysis (DEA), which derive efficiency of units from a few input and output criteria. While DEA is effective for policymakers, BSC is more suitable for individual SME. The proposed method that uses structural equation modeling (SEM) approach to derive the relationship of criteria and criteria weights formulates regressiontype models for a specific region as well as for specific SME. The SEM-based supply chain sustainability performance measurement model is beneficial to policymakers as they can determine means for improvement at a regional level. The proposed method could also facilitate managers/owners of individual SMEs with measures for improving their supply chain sustainability performance. The method has been applied to three varied geographical locations in the UK, France and India in order to demonstrate its effectiveness.
\end{abstract}

Keywords Structural equation modeling (SEM) - SMEs · Supply chain · Sustainability · Performance measurement . The UK . France and India

\section{Introduction}

In comparison to large companies, SMEs have a tendency to be less engaged with environmental management practices and performance, and reduce environmental impact so that green supply chain, waste reduction and low carbon development can be achieved. SMEs are much less likely to have sustainability goals and practices in place (Johnson and Schaltegger 2016). The barriers for SMEs is that environmental measures are typically thought of as expensive, even when cost reduction benefits are highlighted to them (Petts et al. 1998;

Chrisovalantis Malesios

c.malesios@aston.ac.uk

1 Aston University, Birmingham, UK

2 Neoma Business School, Rouen, France 
Simpson et al. 2004). Furthermore, a large proportion of SMEs are unaware of environmental practices and that good sustainability can improve operational efficiencies, reduce costs and risks and provide new opportunities (Ammenberg and Hjelm 2003; Nejati et al. 2016; Roxas et al. 2016). SMEs often lack resources, finances, time and knowledge to implement environmental improvement measures. In comparison, it is easier for larger businesses to invest in corporate social responsibility (CSR) and their long term benefits. Most of all the lack of availability of a standard system for measuring and enhancing sustainability of SMEs increases the problem. SMEs often believe that their firm does not have significant impact on the natural and social environment (Masurel 2007). In other words, SMEs have low sustainability awareness (Prabawani 2013).

Saad et al. (2017) have already pointed out on the differences between SMEs and larger organizations as regards on how the former identify, assimilate, transform, and apply external knowledge that eventually may lead to their awareness, which in turn has positive impacts on their innovation performance (see also Zhai et al. 2018).

SMEs make up the most significant proportion of businesses worldwide (account for over 95\% of all businesses) hence the cumulative environmental impacts of the sector are large (Petts 2000). In particular, Small-and-medium sized enterprises employ $45 \%$ of the workforce in the UK, and the 66\% in the EU (Castka et al. 2004). However, SMEs generally do not implement environmentally friendly practices. Thus, SMEs have been identified as a major problem area in the field of environmental regulation (Williamson and Lynch-Wood 2006). As a result there has been a drive from governments to engage with SMEs on the topics of the environment.

Prior researches reveal that business sustainability could be achieved through the right combination of economic, environmental and social aspects of business. Sustainable supply chain performance management has come up as a way for enhancing sustainability of SMEs. Although there are studies attempting to measure performance of SMEs using various modelling approaches (see Hudson et al. 2001; Garengo et al. 2005 for reviews on methods for measuring performance of SMEs), however, up till now there has not been presented a unified method in order to assess and measure sustainability in SMEs', especially targeted towards sustainable supply chain performance. In addition, the studies of sustainability measurement of SMEs are rather limited (Prabawani 2013).

Different quantitative methods have been proposed in sustainable supply chain performance measurement literature. They could primarily classified into two categories - standalone performance measurement and benchmarking. The balanced scorecard (Hubbard 2009; Lawrence et al. 2006; Rao et al. 2006) is being used extensively for performance measurement, which is quite common in sustainable supply chain performance measurement also (Bhattacharya et al. 2014). As a method of performance measurement in one hand, Data Envelopment Analysis (DEA) (Belu 2009; Wong and Wong 2007), has been applied extensively across the industries and researches. However, DEA is better suitable for the policymakers as it can segregate efficient and inefficient companies with respect to a few objective criteria (inputs and outputs). On the other hand, MCDM techniques (e.g., the Analytic hierarchy process, Analytic network process, Fuzzy theory etc.) are suitable for benchmarking small number of SMEs using multiple criteria and sub-criteria. While criteria weights are not that significant in DEA analysis, the backbone of analysing performance using MCDM technique is to derive criteria weights along with deriving ultimate performance. Additionally, none of the methods are able to establish causal relationship among the criteria, which enable to derive root causes of superior performance.

Therefore, there is a need of an innovative method of SMEs' supply chain sustainability performance measurement that considers robust criteria, their importance, and could be used 
by individual SME's owners/directors and policymakers. Additionally, the model could be used for standalone performance measurement as well as benchmarking along with deriving means for improvement.

The main aim of this research is to develop a robust SMEs' sustainable supply chain performance measurement model in order to objectively improve their sustainability. This research uses Structural Equation Modelling (SEM) to develop regression model for deriving sustainable supply chain performance of specific zone through sampling. This enables policymakers to reveal the state of sustainability of SMEs and deriving means for improvement. Additionally, individual SME can reveal very objectively the means for improving their supply chain sustainability. The paper identifies and proposes the key practice/performance sustainability indicators, from environmental, economic, operational and social perspective. We use real data examples to demonstrate that our approach results in a better overall evaluation of supply chain sustainability measurement in comparison to previous methods. As an outcome of this research, it is anticipated that an individual SME will be able to easily implement the proposed method in order to compare with the average levels of performance in their relative region of interest.

We pose that this method offers certain advantages in comparison to the other quantitative methodologies applied up to now in relevant research literature, such as the simple balanced scorecard method or the data envelopment analysis. In our view, SEM approach is more robust in comparison to the balanced scorecard method that is not based on an overall measurement derived from a unified model, whereas DEA results are mainly useful for policy makers. On the other hand, SEM approach implemented here is a unified methodology based on statistical modelling and the obtained results can be of use both to policy makers and individual SMEs as it will be subsequently shown. Additionally, the latter method, according to the authors' knowledge, has not been previously utilized for the assessment and measurement of sustainability levels of SMEs.

The remainder of the paper is divided into the following main parts. Section 2 reviews the contemporary supply chain sustainability models and identifies the knowledge gaps. Section 3 demonstrates methodology of this research and develops the framework for the SMEs supply chain sustainability performance measurement. Section 4 applies the proposed framework to 120 SMEs across three industrial regions in the UK, France and India and describes the results. Section 5 discusses on the proposed framework along with the significance of the study and original contributions and concludes this research through a few propositions along with scope for further research.

\section{Literature review}

Prior researches on the measurement of supply chain performance of enterprises use mainly the balanced score card approach accompanied by multi-criteria decision-making (MCDM) techniques and the data envelopment analysis. The following paragraphs thoroughly review the contemporary methods for supply chain sustainability performance measurement and identify knowledge gaps that this research intends to bridge. Firstly, we review the papers that have used DEA as performance measurement method and secondly, considered balanced score card approach for performance measurement. Subsequently, specific literature on sustainable supply chain performance measurement has been critically reviewed and knowledge gaps are identified. 
A large number of research associated with applications of DEA on performance measurement and firm benchmarking exists (e.g., Chen and Zhu 2004; Chiu et al. 2011; Easton et al. 2002; Halkos and Salamouris 2004; Saranga and Moser 2010; Soheilirad et al. 2017; Wang et al. 1997). We refer the interested reader to Shewell and Migiro (2016) for a review on the applications of DEA in performance measurement. DEA, which is a non-parametric linear programming approach, evaluates the performance of a set of entities called decision making units (DMUs) by using the observed inputs and outputs of each DMU to calculate its efficiency in relation to all other DMUs in the population. Thus, DEA calculations result in a relative efficiency score for each DMU. Based on this framework, DEA has been extensively used for evaluating the performance of many different types of business units and activities (Shewell and Migiro 2016). Advantages of DEA in performance evaluation rely on the fact that DEA does not rely on prior assumptions such as required for regression analysis and it does not rely on any assumptions of a functional form relating inputs to outputs.

One of the most popular performance management methodologies is the Balanced Scorecard (Hoque 2014; Libby et al. 2004). Introduced by Kaplan and Norton (1992), the balanced score card has been widely used in industry. The Balanced Scorecard's underlying structure usually contains the most important objectives of a company. However, the Balanced Scorecard has been criticized for its underlying assumptions (Nørreklit 2000) and method of creation (Ahn 2005). Typically, the Balanced Scorecard methodology offers ideas for which measures to use, usually included in each of four perspectives, which are financial, customer, internal business process, and learning and growth, and it is not designed to stand alone as a performance measurement tool.

Hence, due to the multiple criteria nature of the balanced scorecard approach, many of its applications are supported by multi-criteria decision-making models. The main idea is to initially create an individualized scorecard that comprehensively captures the most important objectives of a company, which will subsequently provide a sound basis for the use of MCDM methodology. In this respect, MCDM models and methods have been also used extensively for measuring performance in various situations (Barcus and Montibeller 2008; Marques et al. 2010; Chen and Lee 2010). This performance can be measured by various indicators, and various criteria should be assessed.

The literature on providing methods on how to measure a company's (subsequently a SMEs') supply chain sustainability in a quantitative way is rather limited. Research of the relevant literature has shown that most of the attempts focus on the utilization of the balanced scorecard method (see Hubbard 2009; Borga et al. 2009; Lawrence et al. 2006). The balanced scorecard method is one of the most widely applicable performance management methods. Specifically, Hubbard (2009), by following the methodology framework of Hart and Milstein (2003), and combining it with standard balanced scorecard methodology, proposes a sustainability performance index by including environmental, social, economic and operational aspects. In particular, Hubbard (2009) proposes to measure organizational sustainability by including social and environmental issues in the existing standard balanced scorecard to produce a sustainable balanced scorecard for each company that typically consists of measuring four aspects of a business' performance which are: financial, internal process, customers/market and learning and development performance. The additional social and environmental indicators could then be embedded in one of the former four aspects of performance. Alternatively, one may add the environmental and social measures as separate additional aspects of business performance. The author proposes a single organizational sustainability performance index, based on the sustainability balanced scorecard that is simply derived by averaging the individual indicators of the balanced scorecard. 
In another study (Borga et al. 2009), the authors combine economic, social and environmental indicators using the balanced score card to propose guidelines for evaluating the sustainability performance of SMEs. Lawrence et al. (2006) analyse firms' sustainability by comparing the practices over small, medium and large enterprises. Benn et al. (2007) present criteria to describe firms' sustainability level. Rao et al. (2009) propose a metric of corporate environmental indicators for SMEs in the Philippines. Belu (2009) on the other hand, proposes a tool for calculating index rankings of large corporations in terms of their sustainable behavior. To achieve this, the author utilizes data envelopment analysis methodology (Charnes et al. 1978) to evaluate the sustainability performance of 1012 companies listed in the world stock markets. The author utilizes the variables of return of asset, return of investment and average stock return, as the economic indicators of sustainability, and analyzes using DEA how these economic dimensions influence sustainability. Hence, by considering financial performance measures as inputs and sustainability variables' scores as outputs, through DEA efficiency scores are derived. These scores are essentially categorizing companies to optimal and sub-optimal, in the sense that the latter fail to achieve enough when it comes to their sustainable social and environmental practices, given their good economic results.

However, this measure of sustainability approach based on DEA analysis fails to provide specific suggestions on how to improve sustainability of these sub-optimal companies. On the other hand, the balanced score card measurement (e.g., Borga et al. 2009; Hubbard 2009) cannot provide a robust relative measurement of individual sustainability, that can take into account the overall sustainability performance of companies operating in the same country/region, since it is not a model-based methodology.

While the aforementioned methods for performance measurement and evaluation can objectively derive sustainability performance of supply chain, the main shortcomings are two folds. Firstly, the methods are either suitable for policy makers (e.g., DEA based supply chain sustainability performance measurement) or individual SME's managers/directors/owner (e.g., balanced score card approach using MCDM techniques). Secondly, deriving criteria weights using the contemporary methods is not very objective. DEA-based approaches avoid considering criteria weights and MCDM techniques consider decision makers perceptions to derive criteria and sub-criteria weights. Additionally both the methods presume causal relationship of criteria. Prior literatures use structural equation modeling for testing associations between various constructs and sub-constructs of supply chain sustainability but do not focus on developing sustainability performance measurement index for a specific region and individual company (Shibin et al. 2017; Kamarudin and Aslan 2017). Table 14 in the "Appendix" summarizes the main information on previous studies on the measurement of sustainability performance of enterprises including SMEs.

This research bridges this gap by developing a framework for sustainable supply chain performance measurement of SMEs using structural equation modeling. The proposed framework enables measuring performance from policymakers' perspectives, suggests improvement measures and facilitates to make various decisions. Additionally, this could be used for individual SME's supply chain sustainability improvement purpose. The model enables to derive criteria weights very objectively in accordance to the performance achievement of SMEs within a specific zone. The model is capable of deriving sustainable supply chain performance index of SMEs within a specific region, and for individual SME with respect to sustainability practices and performance. This enables to derive improvement measures quite easily and objectively. 


\section{Materials and methods}

The objectives of this research of developing an innovative supply chain performance measurement model for SMEs are fulfilled following a few steps. First, relevant existing sustainable supply chain performance measurement frameworks are critically reviewed to identify criteria, sub-criteria and proxies, and methods for analysis. Second, a conceptual framework is developed with the consideration of sustainable supply chain performance criteria, sub-criteria and proxies for analyzing data using SEM. Third, we develop a questionnaire to gather primary information from SMEs for all the proxies. Forth, the survey is undertaken in three diverse regions (West Midlands in the UK, Normandy in France and Eastern part in India), known for the manufacturing, process and construction SMEs. Threecountry data were gathered in order to examine the influence of different socioeconomic and cultural status and different regulatory mechanisms to our derived results (i.e., compare two developed with an emerging economy as regards the measurement of their sustainability levels). Fifth, the structure equation models are developed using the information of the SMEs' data. Sixth, the models are fitted to derive the performance index for specific region through suitable statistical software. Seventh, we derive various performance information of the participating SMEs in the form of individual comparative performance indices. Finally, the various advantages and shortfalls of the proposed supply chain sustainability performance framework are discussed.

\subsection{The survey and data}

Supply chain characteristics data was gathered from SMEs located in specific regions of the UK, France and India. Each of these regions exhibits certain characteristics and enables to derive useful conclusions on the geographical and socio-economic differences of SMEs regarding their supply chain sustainability performance.

Data collected using a structured questionnaire filled by the selected SMEs' managers, directors and/or owners. The questionnaire was constructed aiming to derive the basic characteristics of SMEs' supply chain. In particular, information was collected on focal company's business (i.e., covering products, services, customers, suppliers, employees and economic), demand (covering customer relationship, customers' requirements, customers' contributions in superior product development and outbound logistics), internal operations (i.e., covering business processes, quality/environmental management, forecasting, inventory management, maintenance, capacity utilization, risk management, waste management etc.), and supply sides (covering supplier relationship, procurement processes and inbound logistics).

Sample size selection for our sample framework has been performed by utilizing simple random sampling. Specifically, for sample size selection, we have used $\hat{p}=0.5$ as an estimate of population proportion that share a certain characteristic on one of the (categorical) variables in the survey. If $e$ is the proportion of error we are prepared to accept between the sampling proportion and the unknown proportion of the population (we accept that $e=10 \%$ ) and with $t$ we denote the value from the standard normal distribution reflecting the confidence level $(t=1.96$ for a $95 \%$ confidence level), then, by relying on the simple random sampling formula we should select approximately 96 SMEs.

Following the suggested sample size, we have collected data on 40 SMEs located in the Midlands, UK, a very productive area of the UK with $11 \%$ of the country's GDP contributed by manufacturing and construction industry in the region. Also, 40 SMEs from the wider Normandy area have been sampled, with the latter region being distinguished for their high 
Table 1 Analytical description of the 26 observed items from the SMEs' questionnaire

\begin{tabular}{ll}
\hline Practices dimensions and indicators & Performance aspects dimensions and indicators \\
\hline Economic & Economic \\
Number of Employees (ECO_PR_1) & Turnover (ECO_PER_1) \\
Infrastructure (ECO_PR_2) & Business growth (ECO_PER_2) \\
Environmental & Environmental \\
Adopting standardized environmental system & Effectiveness of environmental system \\
(ENV_PR_1) & (ENV_PER_1) \\
Waste management practices (ENV_PR_2) & Waste reduction (ENV_PER_2) \\
Energy consumption and emission control & Reduction energy consumption and emissions \\
(ENV_PR_3) & (ENV_PER_3) \\
Social & Social \\
CSR practices (SOC_PR_1) & CSR performance (SOC_PER_1) \\
Health and safety practices (SOC_PR_2) & Health and safety performance (SOC_PER_2) \\
Operational & Operational \\
CRM practices (OPR_PR_1) & Long term relationship with customers \\
SRM practices (OPR_PR_2) & (OPR_PER_1) \\
Standardized business process (OPR_PR_3) & CRM effectiveness (OPR_PER_2) \\
Lean practices (OPR_PR_4) & Demand uncertainties (OPR_PER_3) \\
& Long term relationship with supplier (OPR_PER_4) \\
& SRM effectiveness (OPR_PER_5) \\
& Supply uncertainty (OPR_PER_6) \\
& Business process effectiveness (OPR_PER_7) \\
& Lean effectiveness (OPR_PER_8) \\
\hline & \\
& \\
&
\end{tabular}

levels of manufacturing companies. Finally, in addition to the samples collected from the two developed countries, we have collected information concerning supply chain sustainability from 40 Indian SMEs located in the Eastern parts of the country. In the specific region, productivity, manufacturing and economic sustainability is poor in comparison to the rest of the country. Thus, in total, our sample size comprises of 120 SMEs. The questionnaire that has been developed for capturing supply chain characteristics of SMEs and collected data are available upon request by the corresponding author. The survey used a Likert-type scale for measuring the various sustainability practice and performance indicators (observed items).

An analytical description of the observed items from the questionnaire that were utilized for the construction of the latent factors of SMEs' practices and performance aspects is provided in Table 1 above. Table 15 in the "Appendix" illustrates descriptive statistics for the observed variables. The specific items have been measured using a likert scale taking discrete values from 1 to 5 (except for the items of ECO_PR_1, ECO_PER_1 and OPR_PER_1, measured on a 10-point scale). Detailed information on the relative literature utilized for the selection of the specific indicators is provided in Table 16 in the "Appendix". Table 17 additionally provides an assessment of the models' validity, reliability of the measurements scales in the form of percentages of variance explained by each practice/performance latent factor and Cronbach's alpha, respectively. We additionally examine the robustness of the results by the use of construct (i.e., convergent and discriminant) validity of the latent constructs of the SEM models. Convergent validity is tested through the use of the average variance extracted (AVE) analysis. The value of AVE for each construct should be at least 0.50 (Fornell and Larcker 1981). Discriminant validity has been also examined through comparison of square roots of AVEs with correlation coefficients between the observed items. Square roots of AVEs should be higher than the correlations between constructs/variables. 


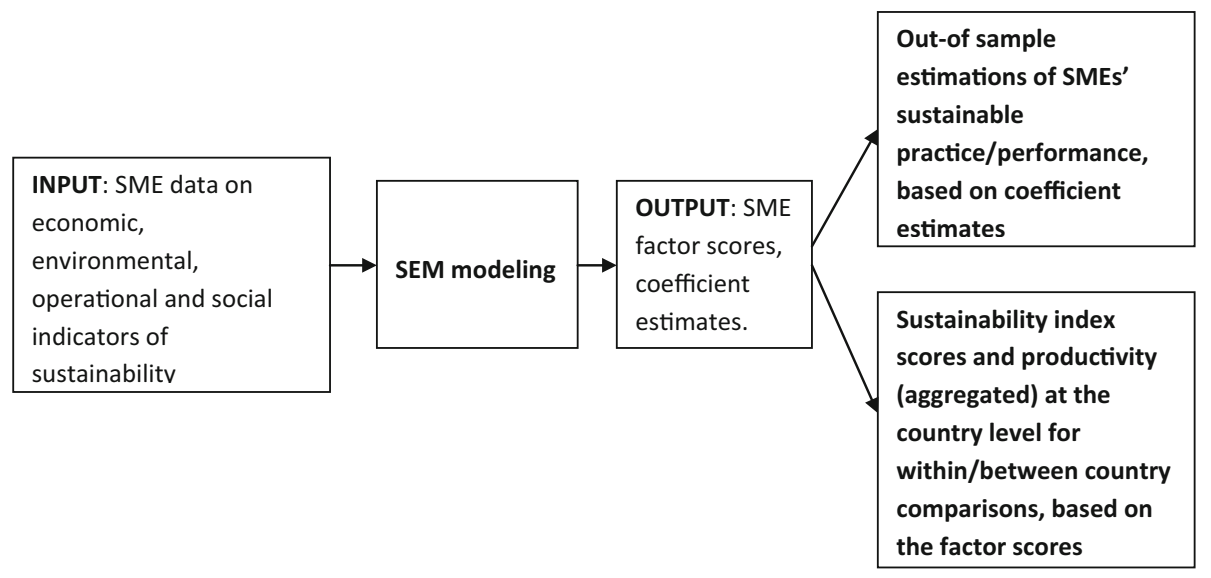

Fig. 1 Step-by-step description of methods of the current study

\subsection{SEM modeling}

We apply structural equation modeling (SEM) (Bollen 1989) methodology to derive a unique sustainability measurement regression-type model. Subsequently, this model can be utilized for deriving a comparative sustainability measure for an individual SME. SEM was considered for this study since it is similar to multiple regression, having though the distinctive characteristic of being able to include latent constructs as dependent and explanatory variables in the regression equation.

The following flowchart presents in a compact way the methodological steps we are following in this study (Fig. 1).

More analytically - as depicted in the previous flowchart- to accomplish the sustainability measurement, data from a carefully selected stratified sample of the UK, French and Indian SMEs are used as input for the analysis, comprising of the measurement of the perceptions of the SEMs owners/managers on specific observed items of environmental, economic, operational and social practices/performances (see Table 1).

Next, follows the second step of SEM modeling application on the collected data, where two different models are fitted to the data, one for the sustainability practices index and another for the sustainability performance index (see the following Figs. 2, 3).

In the above Figures, rectangles of environmental, economic, operational and social practices and performance, represent latent constructs that are realized by combining together information gathered by the individual observed items of the survey (Table 1).

In order to fit the above hypothetical models we assume the following equations for each of the two models (total sample size for complete data: $n=120$ ):

$$
\begin{aligned}
& y_{i j}=\lambda_{j} \xi+\delta_{i j}(i=1,2,3,4 ; j=1,2, \ldots, 120) \\
& y_{i j}=\mu_{j} \zeta+\delta_{i j}(i=5,6,7,8 ; j=1,2, \ldots, 120)
\end{aligned}
$$

where $y_{i j}$ denotes the $j$ th collected measurement on the $i$ th latent factor of practices and performances, respectively, and $\xi$ and $\zeta$ are the $(1 \times 1)$ (unknown) single factors of sustainability practices and performance, respectively (see Figs. 2,3 ). The $\lambda_{j}$ 's and $\mu_{j}$ 's terms are the factor loadings to be estimated connecting factors $\xi$ and $\zeta$ to the $y_{i j}$ 's, and $\delta_{i j}$ is the mea- 


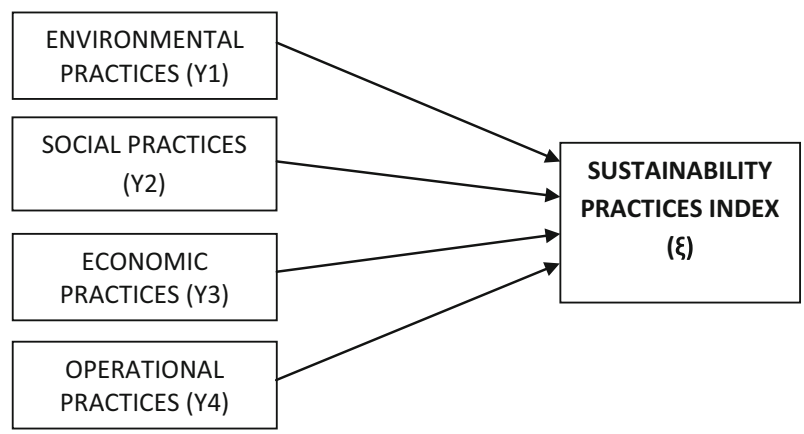

Fig. 2 The conceptual framework for the construction of the sustainability practice index based on Structural equation modeling

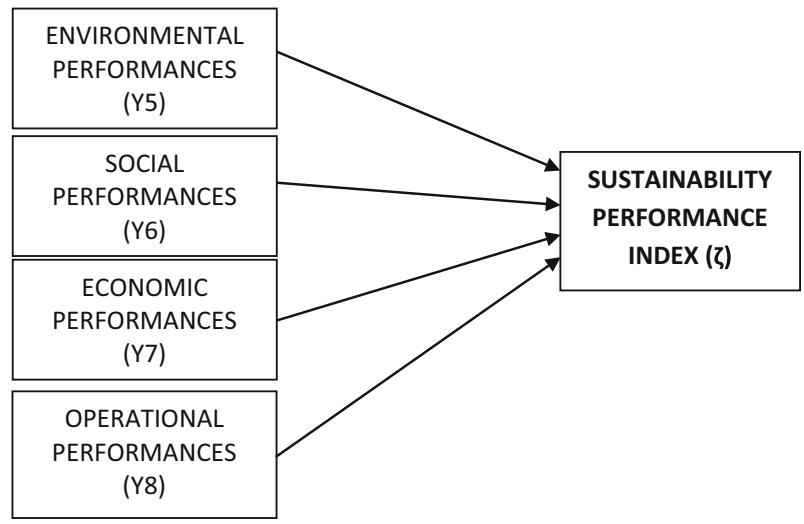

Fig. 3 The conceptual framework for the construction of the sustainability performance index based on structural equation modeling

surement error. It is further assumed that the error terms $\delta_{i j}$ and the common factors $\xi, \zeta$ have a zero mean and that the common and unique factors are uncorrelated, i.e., $\mathrm{E}(\xi-\mathrm{E}(\xi))\left(\delta_{i j}\right.$ $\left.-\mathrm{E}\left(\delta_{i j}\right)\right)=0$ and $\mathrm{E}(\zeta-\mathrm{E}(\zeta))\left(\delta_{i j}-\mathrm{E}\left(\delta_{i j}\right)\right)=0$.

The factors of sustainability practices/performances are subsequently related to the observed items from the SMEs' questionnaire, denoted by $x_{i j}$, through the following set of equations:

$$
\begin{aligned}
& x_{i j}=\kappa_{j} y_{i j}+\varepsilon_{i j}(i=1,2,3,4 ; j=1,2, \ldots, 120) \\
& x_{i j}=v_{j} y_{i j}+\varepsilon_{i j}(i=5,6,7,8 ; j=1,2, \ldots, 120)
\end{aligned}
$$

The two above described SEM models are fit by the weighted least squares method (Jöreskog 1970) to derive the parameter estimates. Model estimation was performed with the use of the AMOS software (Arbuckle 2014).

As output of the previously described performed models we calculate individual sustainability index values, separately for practices and performances, for each SME by fitting the SEM models to the aggregated data of each region (see Fig. 1, step 3).

Applying structural equation modeling enables us to obtain factor scores that derive from the estimates of beta coefficients of the regression equation that relates each latent construct 
Table 2 Values of goodness-of-fit measures for assessing SEM model fit

\begin{tabular}{|c|c|c|c|c|}
\hline & \multicolumn{4}{|c|}{ Fit statistics } \\
\hline & PGFI & GFI & AGFI & RMSEA \\
\hline \multicolumn{5}{|c|}{ Practice model } \\
\hline Midlands & 0.791 & 0.848 & 0.782 & 0.06 \\
\hline Normandy & 0.689 & 0.787 & 0.695 & 0.07 \\
\hline $\begin{array}{c}\text { Eastern } \\
\text { India }\end{array}$ & 0.761 & 0.805 & 0.720 & 0.07 \\
\hline \multicolumn{5}{|c|}{ Performance model } \\
\hline Midlands & 0.604 & 0.758 & 0.654 & 0.09 \\
\hline Normandy & 0.589 & 0.752 & 0.677 & 0.08 \\
\hline $\begin{array}{c}\text { Eastern } \\
\text { India }\end{array}$ & 0.646 & 0.712 & 0.655 & 0.09 \\
\hline
\end{tabular}

(response variable) with the selected individual items of practices/performances (explanatory variables). These factor scores can be considered as a combined measure of sustainability practice and performance of each SME on the basis of an environmental, economic, operational and social perspective. By aggregating these index scores at the regional level, we get an index that can be considered as the average performance measure of sustainability in each local cluster of SMEs. Based on these calculated measures one can compare an SMEs' performance with the average performance of the relative SMEs.

Moving one step further, the individual factor scores obtained by regarding the overall latent construct of sustainability practice/performance as the response variable, may be regarded as measures of the overall sustainability from the practices/performance view of an individual SME.

\section{Results of structural equation modeling}

In the current section the results of SEM used to measure sustainability supply chain of SMEs are presented. We have fitted six separate structural equation models utilizing the collected data on sustainability practices and performance in the three industrial regions. The fitted SEM models for the purposes of the study were estimated through the AMOS software (Arbuckle 2014). For deriving parameter estimates we have used the method of weighted least squares, due to the nature of the collected data.

\subsection{Measurement of sustainability at the regional level}

Overall, the model fit of the SEM models for practices and performances was moderate to good, as revealed by the goodness-of-fit statistics (Hu and Bentler 1999) presented in Table 2). Typically, for a good fit the indices should be above 0.9. The Root Mean Square Error of Approximation (RMSEA) should be small (typically less than 0.05).

However these cut-off thresholds have been often criticized. For example, in Marsh et al. (2004) there are strong evidence based on a theoretical rationale suggesting caution in following the stringent cutoff threshold values proposed by Hu and Bentler (1999). Along the same lines, Heene et al. (2011) state that "In particular, the cutoff values cannot be interpreted 
Table 3 standardized regression weights for the practice and performance SEM models

\begin{tabular}{lllllllc}
\hline & \multicolumn{2}{l}{ Practice dimensions } & & & \multicolumn{3}{l}{ Performance dimensions } \\
& Midlands & Normandy & Eastern India & & Midlands & Normandy & Eastern India \\
\hline ECON & 0.53 & 0.55 & 0.64 & 0.54 & 0.52 & 0.35 \\
ENV & 0.5 & 0.55 & 0.43 & 0.44 & 0.46 & 0.15 \\
SOC & 0.53 & 0.54 & 0.56 & & 0.59 & 0.54 & 0.84 \\
OPR & 0.42 & 0.33 & 0.3 & & 0.42 & 0.47 & -0.39 \\
\hline
\end{tabular}

as golden rules or even given as a fixed value independent of the data given". Also, cut-off threshold values for the goodness-of-fit criteria heavily depends on sample size and model complexity (see also Iacobucci 2010, for another discussion on the subject).

Validity and reliability of the fitted SEM models has been also examined through suitable measures (Table 17), with the obtained values verifying at a large part the robustness of the statistical analysis results. Note that especially concerning the obtained values of Cronbach's alpha, there are many suggestions for Cronbach's alpha having an acceptable threshold of $>0.6$ (see, e.g., Bryman and Cramer 2005; Griethuijsen et al. 2014; Hair et al. 2006). For our analysis, majority of the alpha values range above the acceptable threshold of 0.6. In addition, we should note that the observed items utilized in order to form each latent factor for our SEM analysis are primarily used under a formative perspective, i.e., they have been (pre)-selected based on preliminary research through thorough literature review and consulting from experts in the field, hence, we are mostly interested in examining the hypothesized associations between the specific observed items and the corresponding latent construct.

In Table 3 the estimated (standardized) regression weights of the association between the various dimensions with the latent construct of sustainability are given.

Thus, for instance, the sustainability practices and performance in the Midlands SMEs' is dependent on the following equations, respectively:

Sustainability practices

$$
\begin{gathered}
=0.53 \times[\text { Economic practices }]+0.5 \times[\text { Environmental practices }] \\
+0.53 \times[\text { Social practices }]+0.42 \times[\text { Operational practices }]
\end{gathered}
$$

$$
\begin{aligned}
& \text { Sustainability performance } \\
& \begin{aligned}
= & 0.54 \times[\text { Economic performance }]+0.44 \times[\text { Environmental performance }] \\
& +0.59 \times[\text { Social performance }]+0.42 \times[\text { Operational performance }]
\end{aligned}
\end{aligned}
$$

The above results can provide some indications on the overall relative impacts of each separate sub-construct of sustainability practice and performance on the sustainability measurement. For instance, if we take a look at the regression weights for sustainability practice equation between Midlands and Eastern India, we observe that the sustainability index of the former is evenly impacted by the economic, environmental and social sub-constructs, whereas SMEs of Eastern India are mostly impacted by the economic and social practice indicators.

Next, upon obtaining the factor scores of each one of the sample SMEs, we are able to calculate aggregate measurements of the sustainability levels of SMEs in each one of the three selected regions of interest. As previously mentioned, this study provides feedback to the 
Table 4 Average sustainability practices measurement score (Midlands)

\begin{tabular}{lllll}
\hline $\begin{array}{l}\text { Sustainability } \\
\text { practices } \\
\text { dimensions }\end{array}$ & Average score & SD & Minimum & Maximum \\
\hline $\begin{array}{l}\text { Economic practices } \\
\begin{array}{l}\text { Operational } \\
\text { practices }\end{array}\end{array}$ & 4.15 & 2.19 & 1.06 & 8.89 \\
$\begin{array}{l}\text { Environmental } \\
\text { practices }\end{array}$ & 2.18 & 0.72 & 0.93 & 3.67 \\
$\begin{array}{l}\text { Social practices } \\
\begin{array}{l}\text { Sustainability } \\
\text { practices }\end{array}\end{array}$ & 1.51 & 0.51 & 0.85 & 2.54 \\
\hline
\end{tabular}

Table 5 Average sustainability performance measurement score (Midlands)

\begin{tabular}{lllll}
\hline $\begin{array}{l}\text { Sustainability } \\
\text { performance } \\
\text { dimensions }\end{array}$ & Average score & SD & Minimum & Maximum \\
\hline $\begin{array}{l}\text { Economic } \\
\text { performance }\end{array}$ & 3.13 & 1.76 & 1.03 & 7.86 \\
$\begin{array}{l}\text { Operational } \\
\text { performance }\end{array}$ & 2.38 & 0.66 & 1.11 & 3.65 \\
$\begin{array}{c}\text { Environmental } \\
\text { performance }\end{array}$ & 1.36 & 0.46 & 0.72 & 2.17 \\
$\begin{array}{l}\text { Social performance } \\
\begin{array}{l}\text { Sustainability } \\
\text { performance }\end{array}\end{array}$ & 1.41 & 0.76 & 0.93 & 3.73 \\
\hline
\end{tabular}

policymakers to review their current policies and enable them to act locally in certain areas. Specifically, SEM modeling on the relationship between the latent construct of sustainability with practice and performance dimensions allows one to derive a unique sustainability score for each single SME in the dataset used for running the SEM analysis. Individual sustainability factor scores are calculated through the use of standardized regression weights combined with the observed collected data on sustainability practices and performance of each SME in the sample. Based upon these individual scores, we are able to calculate aggregate regional scores by summarizing the former, e.g., through the measurement of regional averages. Similarly, aggregate scores can be calculated for each one of the sub-constructs of practices and performance dimensions, utilizing the estimated standardized regression weights of the observed items of practices and performance. Hence, these obtained aggregate indices can be used as a benchmark for the sustainability performance of each individual SME of the specific region. Tables 4, 5, 6, 7, 8 and 9 show the average sustainability index scores with respect to sustainability practices and performances for the Midlands, Normandy and Eastern India, respectively.

In Tables 4 and 5 the average sustainability indices with respect to practices and performance for the SMEs based in Midlands are provided. For a visual representation of the latter results see Fig. 4 in the "Appendix". 
Table 6 Average sustainability practices measurement score (Normandy)

\begin{tabular}{lllll}
\hline $\begin{array}{l}\text { Sustainability } \\
\text { practices } \\
\text { dimensions }\end{array}$ & Average score & SD & Minimum & Maximum \\
\hline $\begin{array}{l}\text { Economic practices } \\
\begin{array}{l}\text { Operational } \\
\text { practices }\end{array}\end{array}$ & 4.42 & 3.04 & 1.03 & 0.49 \\
$\begin{array}{l}\text { Environmental } \\
\text { practices }\end{array}$ & 1.78 & 0.69 & 1.23 & 3.13 \\
$\begin{array}{l}\text { Social practices } \\
\text { Sustainability } \\
\text { practices }\end{array}$ & 2.33 & 0.72 & 0.92 & 3.69 \\
\hline
\end{tabular}

Table 7 Average sustainability performance measurement score (Normandy)

\begin{tabular}{llccc}
\hline $\begin{array}{l}\text { Sustainability } \\
\text { performance } \\
\text { dimensions }\end{array}$ & Average score & SD & Minimum & Maximum \\
\hline $\begin{array}{l}\text { Economic } \\
\text { performance }\end{array}$ & 2.41 & 1.93 & 0.91 & 6.91 \\
$\begin{array}{l}\text { Operational } \\
\text { performance }\end{array}$ & 2.25 & 1.32 & -0.71 & 4.23 \\
$\begin{array}{l}\text { Environmental } \\
\text { performance }\end{array}$ & 2.35 & 0.64 & 1.13 & 3.61 \\
$\begin{array}{l}\text { Social performance } \\
\text { Sustainability } \\
\text { performance }\end{array}$ & 1.88 & 0.87 & 0.86 & 3.44 \\
\hline
\end{tabular}

Table 8 Average sustainability practices measurement score (Eastern India)

\begin{tabular}{lllll}
\hline $\begin{array}{l}\text { Sustainability } \\
\text { practices } \\
\text { dimensions }\end{array}$ & Average score & SD & Minimum & Maximum \\
\hline $\begin{array}{l}\text { Economic practices } \\
\begin{array}{l}\text { Operational } \\
\text { practices }\end{array}\end{array}$ & 4.54 & 2.17 & 1.16 & 9.51 \\
$\begin{array}{l}\text { Environmental } \\
\text { practices }\end{array}$ & 1.27 & 0.41 & 0.60 & 2.07 \\
$\begin{array}{l}\text { Social practices } \\
\text { Sustainability } \\
\text { practices }\end{array}$ & 1.83 & 0.42 & 0.65 & 2.97 \\
\hline
\end{tabular}

As one observes, SMEs based in the Midlands have high index scores on the economic sustainable practices and performance (average scores: 4.15 and 3.13, respectively), followed by the raised values on the operational sustainable practices/performance (average scores: 2.18 and 2.38, respectively). On the other hand, based on the managers' perceptions, their 
Table 9 Average sustainability performance measurement score (Eastern India)

\begin{tabular}{lllll}
\hline $\begin{array}{l}\text { Sustainability } \\
\text { performance } \\
\text { dimensions }\end{array}$ & Average score & SD & Minimum & Maximum \\
\hline $\begin{array}{c}\text { Economic } \\
\text { performance }\end{array}$ & 1.22 & 0.26 & 0.61 & 1.60 \\
$\begin{array}{c}\text { Operational } \\
\text { performance }\end{array}$ & 2.96 & 0.67 & 1.46 & 3.42 \\
$\begin{array}{c}\text { Environmental } \\
\text { performance }\end{array}$ & 0.52 & 0.71 & -1.11 & 1.56 \\
$\begin{array}{c}\text { Social performance } \\
\begin{array}{c}\text { Sustainability } \\
\text { performance }\end{array}\end{array}$ & 2.63 & 0.71 & 0.94 & 3.94 \\
\hline
\end{tabular}

social practice and performance ranges at low levels, with an average index score of 1.43 and 1.41 for practices and performances, respectively.

The overall sustainability practice index score for an SME company based in the Midlands, UK is estimated at the average value of 0.84 , according to the measurement obtained from our analysis (Table 4). The corresponding average index score for the sustainable performance of SMEs is estimated at 0.76 (Table 5). Again, the lowest aggregate index scores are shown for the environmental and social performance dimensions.

Next we may look at the results obtained for the SMEs located in Normandy, France (Tables 6, 7 and Fig. 5 in the "Appendix"). It is seen from the inspection of the results that these SMEs perceive higher their sustainable economic practices (avg score index 4.42), followed by the sustainable environmental practices (avg score index 2.33). In contrast to the Midlands-based SMEs, operational practices are ranked lower (avg score index 1.78).

As regards the measurement of French SMEs sustainability performance, it is observed that their sustainability economic performance is considerably lower in comparison to the practices (avg score index 2.41). Operational and environmental performance indices are ranging at the same levels ( 2.25 and 2.35 , respectively).

The general average sustainability indices for practices and performance are 0.71 and 0.61 , respectively.

Finally, Tables 8 and 9 (see also Fig. 6 in the "Appendix") present the corresponding results for the SMEs based in Eastern India. Here the results are clearly distinct from the results of the two developed countries of UK and France. Indeed, although sustainable economic practices are quite high (avg score index 4.54), the corresponding economic performance is very low (avg score index 1.22). Another distinctive characteristic of SMEs located in Eastern India is that they exhibit quite high index scores as regards their perceptions on their sustainable social practice and performance (avg index scores 2.53 and 2.63, respectively).

With respect to the sustainable operational practices and performance, we see a considerable increase of the average index when moving from practice to performance (average scores 1.27 and 2.96, respectively).

Reversely, although the levels of sustainable environmental practices are high (1.83), the corresponding performance drops to low levels (0.52). The overall sustainability performance of Eastern India SMEs is quite high as regards practices (avg index score 0.84), dropping dramatically though when it realizes through the measured performance (avg index score $0.51)$. 
The above analysis of the results reveal that the policy makers (e.g., the decision makers in local city councils and/or other concerned governmental representatives) can make use of this information to understand the state of SMEs' sustainability performance in a specific zone. This would facilitate them to make both strategic and planning decisions (e.g., capital and revenue budgeting) for the region. The results clearly reveal which construct of the sustainability is strong or weak and due to what reasons. This enables policymakers to formulate focused improvement programs for specific region, which likely to more effective than traditional way of budget allocating for achieving sustainability.

\subsection{Measurement of sustainability at the individual SME level}

The next tables (Tables 10,11) show the factor score weights of the general sustainability measurement construct as well as those for the environmental, economic, social and operational sustainability measures, for the practices and performances, respectively.

Tables 10 and 11 present the factor score estimates derived from the fit of the structural equation models fitted to the three regional datasets, respectively.

In particular, Table 10 contains the factor scores as were estimated from the practice measurement models, whereas the corresponding performance measurement estimates are shown in Table 11.

These scores may assist in the generalization of the results obtained from our analysis, in the sense that SMEs owners/managers of the three selected regions can utilize these estimates in order to calculate their own sustainability indices, once they supply the corresponding levels of their SME scores on the various practice and performance items.

\subsection{Application of SEM modeling to selected individual SMEs}

The last step of our analysis, involves a case study research to validate the results of sustainable supply-chain measurement based on SEM modeling. Individual SMEs are evaluated by combining their questionnaire item scores with the SEM modeling overall regional estimates to produce their sustainability level scores, which are subsequently compared to the average regional sustainability score. In particular, we have randomly chosen three cases from each region and examine at the individual level, the derived results of our measurement in order to evaluate the current state of the companies in terms of their sustainability levels of both practices and performance and to further suggest potential improvements of their performance.

The results on the nine selected cases studies are presented in two Tables, for the practices and performances, respectively (Tables 12, 13). By inspecting the data of Table 12, we are able to see the overall sustainability index with respect to practices of the selected SMEs, along with the rankings on the individual sustainability indicators of the latter companies as they were measured by the distributed questionnaires to the managers/owners.

For example, consider an SME based in the wider region of Midlands, UK, (case study B) which seeks to establish a measurement of the company's sustainability level. In order to calculate its sustainability practice measurement score, one has to combine the individual score values on the company's practices (Table 12) with the coefficient estimates for the sustainability practices model of Table 10, corresponding to the Midland data. Then the practices sustainability index, say $S I_{B}$, of the company will be: 


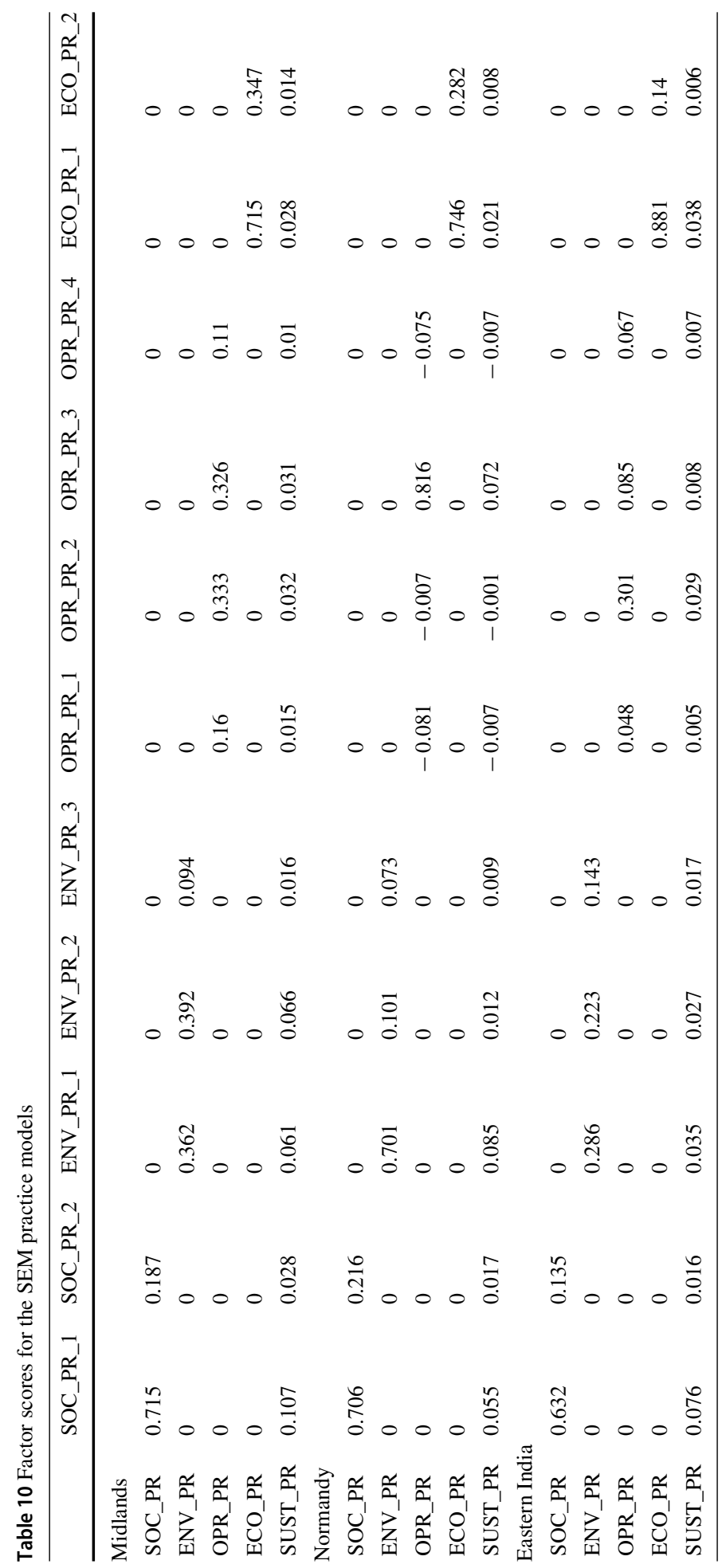




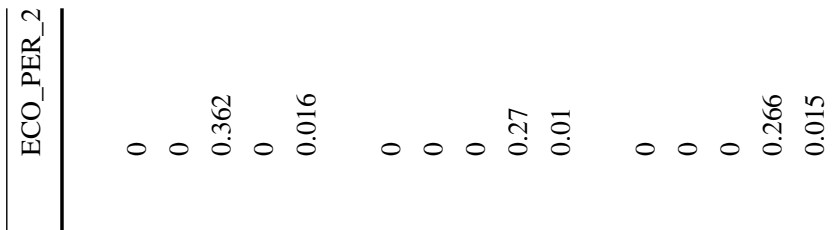

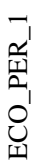

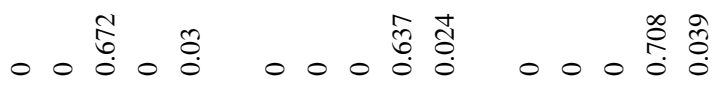

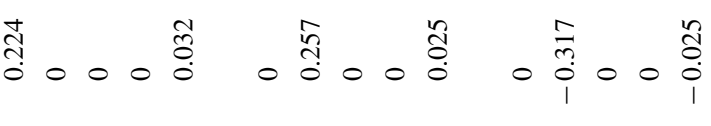

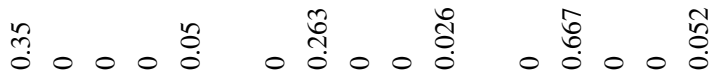

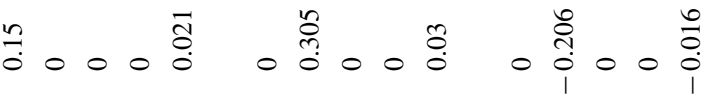

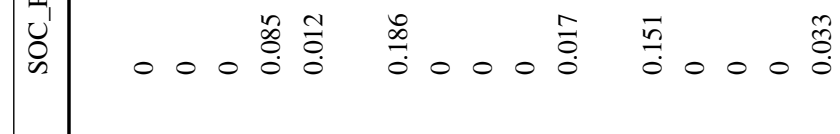

$$
\begin{aligned}
& \begin{array}{r}
a \\
\frac{a}{4} \\
0 \\
0 \\
0
\end{array}
\end{aligned}
$$

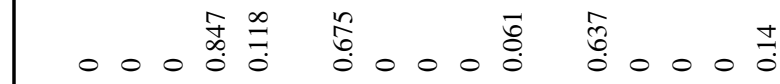




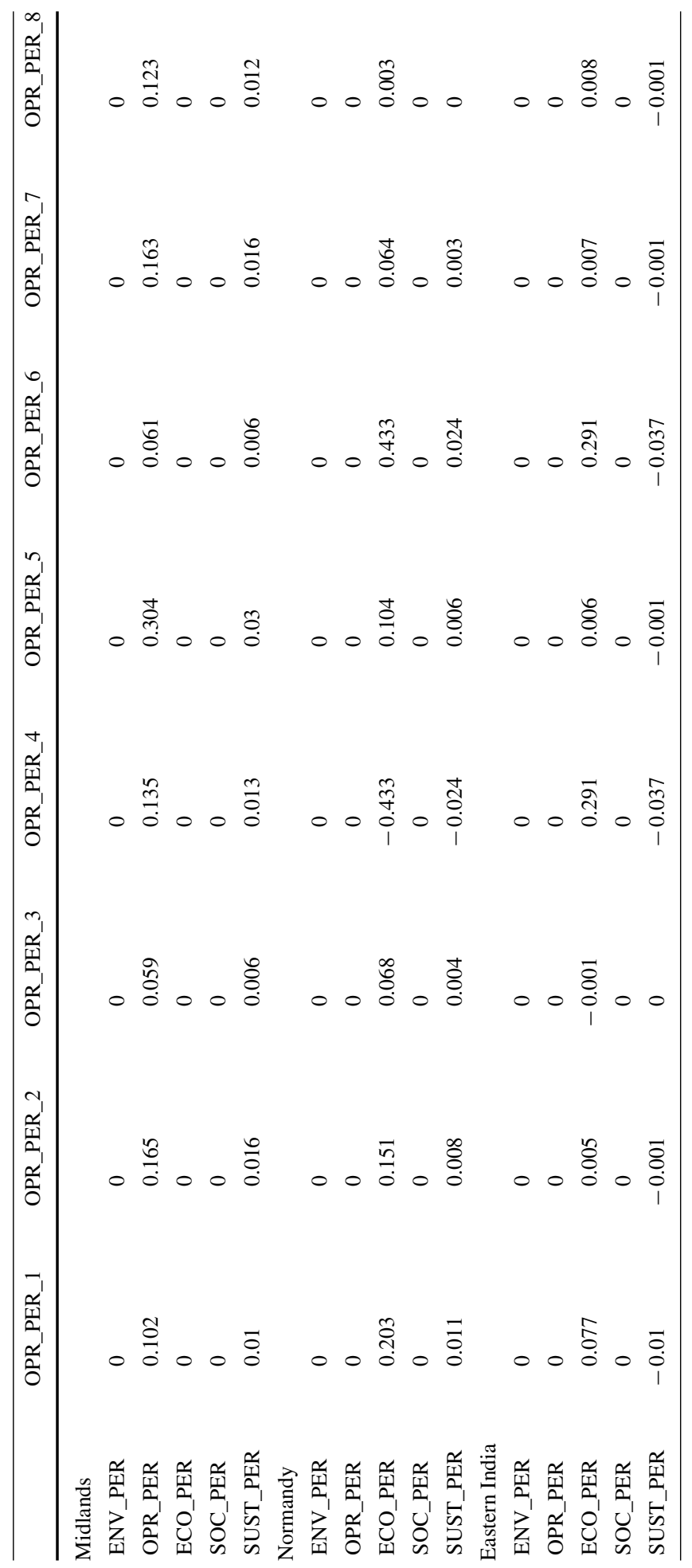


Table 12 Sustainability indicators and corresponding estimates of sustainability practice indices for selected case studies

\begin{tabular}{|c|c|c|c|c|c|c|c|c|c|}
\hline & \multicolumn{3}{|c|}{ Midlands, UK } & \multicolumn{3}{|c|}{ Normandy, France } & \multicolumn{3}{|c|}{ Eastern India } \\
\hline & A & B & $\mathrm{C}$ & D & E & $\mathrm{F}$ & G & $\mathrm{H}$ & I \\
\hline ECON_PR_1 & 4 & 6 & 10 & 4 & 1 & 1 & 4 & 9 & 3 \\
\hline ECON_PR_2 & 1 & 3 & 4 & 2 & 1 & 1 & 4 & 3 & 2 \\
\hline $\begin{array}{l}\text { ECON PRACTICE } \\
\text { INDEX }\end{array}$ & 3.21 & 5.33 & 8.54 & 3.55 & 1.03 & 1.03 & 4.08 & 8.35 & 2.92 \\
\hline OPR_PR_1 & 1 & 3 & 4 & 4 & 2 & 1 & 1 & 1 & 1 \\
\hline OPR_PR_2 & 2 & 3 & 4 & 2 & 2 & 2 & 1 & 2 & 1 \\
\hline OPR_PR_3 & 2 & 3 & 3 & 3 & 1 & 1 & 4 & 4 & 3 \\
\hline OPR_PR_4 & 1 & 1 & 3 & 1 & 1 & 1 & 5 & 4 & 3 \\
\hline $\begin{array}{l}\text { OPR PRACTICE } \\
\text { INDEX }\end{array}$ & 1.59 & 2.57 & 3.28 & 2.36 & 0.89 & 0.97 & 1.01 & 1.22 & 0.79 \\
\hline ENV_PR_1 & 2 & 2 & 3 & 4 & 2 & 2 & 3 & 4 & 2 \\
\hline ENV_PR_2 & 2 & 1 & 3 & 5 & 1 & 1 & 2 & 2 & 2 \\
\hline ENV_PR_3 & 2 & 1 & 3 & 3 & 3 & 3 & 4 & 3 & 3 \\
\hline $\begin{array}{l}\text { ENV PRACTICE } \\
\text { INDEX }\end{array}$ & 1.7 & 1.21 & 2.54 & 3.53 & 1.37 & 1.37 & 1.88 & 1.88 & 1.3 \\
\hline SOC_PR_1 & 3 & 1 & 2 & 2 & 1 & 1 & 4 & 4 & 4 \\
\hline SOC_PR_2 & 3 & 2 & 3 & 4 & 1 & 1 & 3 & 3 & 3 \\
\hline $\begin{array}{l}\text { SOC PRACTICE } \\
\text { INDEX }\end{array}$ & 2.71 & 1.09 & 1.99 & 2.28 & 0.92 & 0.92 & 2.93 & 2.93 & 2.93 \\
\hline $\begin{array}{l}\text { SUSTAINABILITY } \\
\text { PRACTICE INDEX }\end{array}$ & 0.97 & 0.82 & 1.37 & 0.91 & 0.35 & 0.35 & 0.85 & 1.06 & 0.71 \\
\hline
\end{tabular}

$$
\begin{aligned}
S I_{B}= & 0.107 \times 1+0.028 \times 2+0.061 \times 2+0.066 \times 1+0.016 \times 1+0.015 \times 3+0.032 \times 3+0.031 \times 3 \\
& +0.01 \times 1+0.028 \times 6+0.014 \times 3 \approx 0.82
\end{aligned}
$$

This value can then be compared with the aggregated average sustainability values in the Midlands. In this way, individual SMEs can compare with the corresponding regions' average indicators (see aggregated regional results of Tables 4, 5, 6, 7, 8, 9), identify strengths and weaknesses and moreover measure the marginal contribution of each individual sustainability indicator to the overall sustainability practices index, or to the specific environmental, economic, operational and social sustainability indices. For instance, let us consider the Midland-based SME B, with a sustainability practices index score of 0.82 which is slightly below the average of this region (Midlands sustainability average score: 0.84 ). As we observe from Table 12, although the company performs well on the economic aspects of sustainability practices, with an estimated economic sustainability index of 5.33 and respective indicators are 6 and 3 (regional average score 4.15), the company lacks substantially in its performance on environmental and social aspects of sustainability practices (index scores are 1.21 and 1.09, respectively, with corresponding regional averages being 1.51 and 1.43). Hence, by concentrating more on the two latter aspects it is anticipated that the specific company will achieve an enhancement of its sustainability levels. 
Table 13 Sustainability indicators and corresponding estimates of sustainability performance indices for selected case studies

\begin{tabular}{|c|c|c|c|c|c|c|c|c|c|}
\hline & \multicolumn{3}{|c|}{ Midlands, UK } & \multicolumn{3}{|c|}{ Normandy, France } & \multicolumn{3}{|c|}{ Eastern India } \\
\hline & A & B & $\mathrm{C}$ & $\mathrm{D}$ & $\mathrm{E}$ & $\mathrm{F}$ & G & $\mathrm{H}$ & I \\
\hline ECON_PER_1 & 2 & 2 & 8 & 9 & 1 & 1 & 5 & 5 & 4 \\
\hline ECON_PER_2 & 1 & 3 & 3 & 4 & 1 & 1 & 4 & 4 & 3 \\
\hline $\begin{array}{l}\text { ECON } \\
\text { PERFORMANCE } \\
\text { INDEX }\end{array}$ & 1.71 & 2.43 & 6.46 & 6.81 & 0.91 & 0.91 & 1.26 & 1.26 & 0.95 \\
\hline OPR_PER_1 & 1 & 2 & 3 & 6 & 6 & 5 & 3 & 4 & 3 \\
\hline OPR_PER_2 & 1 & 3 & 3 & 3 & 3 & 3 & 4 & 5 & 4 \\
\hline OPR_PER_3 & 1 & 2 & 2 & 4 & 5 & 2 & 2 & 6 & 3 \\
\hline OPR_PER_4 & 2 & 1 & 4 & 3 & 1 & 1 & 2 & 2 & 2 \\
\hline OPR_PER_5 & 2 & 2 & 4 & 4 & 3 & 3 & 4 & 4 & 5 \\
\hline OPR_PER_6 & 2 & 2 & 4 & 2 & 4 & 4 & 2 & 2 & 2 \\
\hline OPR_PER_7 & 2 & 2 & 3 & 2 & 2 & 3 & 4 & 4 & 4 \\
\hline OPR_PER_8 & 1 & 1 & 2 & 1 & 1 & 1 & 4 & 4 & 3 \\
\hline $\begin{array}{l}\text { OPR } \\
\text { PERFORMANCE } \\
\text { INDEX }\end{array}$ & 1.78 & 2.13 & 3.65 & 2.05 & 3.71 & 3.36 & 1.5 & 1.58 & 1.49 \\
\hline ENV_PER_1 & 1 & 2 & 2 & 5 & 2 & 2 & 5 & 4 & 4 \\
\hline ENV_PER_2 & 3 & 2 & 2 & 3 & 1 & 1 & 4 & 4 & 5 \\
\hline ENV_PER_3 & 2 & 2 & 2 & 3 & 3 & 3 & 4 & 4 & 3 \\
\hline $\begin{array}{l}\text { ENV } \\
\text { PERFORMANCE } \\
\text { INDEX }\end{array}$ & 1.65 & 1.45 & 1.45 & 3.09 & 1.64 & 1.64 & 0.37 & 0.58 & 1.56 \\
\hline SOC_PER_1 & 3 & 1 & 1 & 3 & 1 & 1 & 4 & 4 & 4 \\
\hline SOC_PER_2 & 3 & 3 & 2 & 3 & 3 & 3 & 3 & 3 & 3 \\
\hline $\begin{array}{l}\text { SOC } \\
\text { PERFORMANCE } \\
\text { INDEX }\end{array}$ & 2.8 & 1.1 & 1.02 & 2.58 & 1.23 & 1.23 & 3 & 3 & 3 \\
\hline $\begin{array}{l}\text { SUSTAINABILITY } \\
\text { PERFORMANCE } \\
\text { INDEX }\end{array}$ & 0.88 & 0.68 & 0.99 & 0.9 & 0.51 & 0.49 & 0.75 & 0.75 & 0.79 \\
\hline
\end{tabular}

In another example, SME H located in Eastern India has a sustainability practices index of 1.06, higher than the regional average (0.84). When we examine each separate indicator of sustainability we observe that the company scores very high as regards its economic aspects of sustainable practices (8.35 compared to a regional average of 4.54). In addition, despite that the overall sustainable operations practices index is relatively high, the specific company may improve on the latter index by concentrating more on the individual operational indicator of CRM practices (OPR_PR_1). Also this SME_-although achieving a very high ranking on economic practices of sustainability - on the other hand performs poor on the operational practices. As concerns the social practices, the measurement index is relatively high when compared with the specific region's average score as seen in Table 8 (2.53). 
Thus, we see that although the company outperforms in a single sustainability practice dimension, its overall index is suitably weighted to account for the company's performance on the other dimensions.

Finally, by inspecting the corresponding results on the same case studies with respect to their sustainable performance index scores, we are able to obtain indications as to what degree the SMEs' practice implementation has achieved its purposes. As we observe from the results of Table 13, both SMEs underperformed on the economic performance scores with respect to their economic practice scores, with all remaining performance indices ranging at similar levels, except for the environmental performance score of company $\mathrm{H}$, that is significantly lower compared to the environmental practice score. The latter indicates that the specific company although effectively implementing environmental practices, this results in underperformance or poor environmental performance.

The above analysis shows that any SME within a specific region is able to derive their sustainability practice and performance that allow them determining means for improving overall sustainability performance. Sustainability practices with respect to economic, operational, environmental and social measures would lead sustainability performance. Therefore, in accordance with the results, SMEs would identify areas for improvement and undertake improvement projects. These projects are likely to enhance overall sustainability performance of the SME concerned along with improving specific sustainability performance that the SME currently lags.

\section{Discussion and concluding remarks}

The main aim of this research is to develop a supply chain sustainability measurement model for SMEs that can not only dynamically measure the sustainability performance of group of SMEs but also for individual SME along with objectively deriving means for improvement. This study uses structural equation modeling to develop regression models for sustainability practices and performance using various constructs (e.g., economic, operational, environmental and social), sub-constructs and proxies for specific region. First, a conceptual model for performance measurement of a group of SMEs is developed. The model consists of a few criteria, sub-criteria, and proxies. Second, a questionnaire is prepared to capture perception of participating SMEs' representatives. Third, sample SMEs are selected for the study and responses to questionnaire are gathered. Forth, responses are processed using SEM that leads to formulate regression type supply chain sustainability model for SMEs in a specific region. Any SME in that region can measure their absolute supply chain sustainability performance by fitting their data into the region's regression-type model. The outcome i.e., supply chain sustainability performance of specific SME could be compared with the region's average in order to derive the means for improvement. The improvement projects will amend sustainability practices, which in turn affect positively sustainability performances. This method could be used by policy makers as well SMEs' owners, decision-makers and managers. Specific region's data analysis will reveal strengths and weakness of sustainability practices performances of SMEs that helps in deriving means for improvement. This enables policy makers to make planning decisions for SMEs sustainability. On the other hand, individual SME's supply chain sustainability performance is derived using the regional model and feeding the survey data of specific SME into the model. This results in absolute values on practices and performances of sample SMEs with respect to their economic, operational, environmental and social levels of sustainability. Additionally, the overall performance of the participating 
SMEs is also revealed. The contemporary approaches such as balanced score card based performance measurement model and DEA-based efficiency measurement method are unable to provide such robust information.

The current study also explores the possibility of using structural equation modeling as a measurement model for sustainability measurement of SMEs' supply chain through individual indicators of sustainability and its sub-constructs. Our results and examples illustrate that our proposed method could provide an objective picture of a SMEs sustainability performance. In general, our results indicate that the method of rating supply chain sustainability performance introduced in this paper significantly improves previous methods such as balanced score card approach and efficiency measurement using DEA. Our methodology provides a more general picture of the SME's sustainability performance, by combining various indicators of sustainability practices and performance of a relative sample of SMEs to derive the overall sustainability ranking of the particular SME. We have illustrated that our proposed methodology can assist both the policy makers and the individual SMEs, the former by providing them with information in the form of aggregate indices of sustainability, to review the sustainability performance of their own region and compare with other regions. In this way, policymakers can adjust and set their own strategies and targets for SME sustainability development. On the other hand, individual SMEs can benefit from our results by giving them the ability to calculate their own sustainability indices, identify their strengths and weaknesses by comparing with the average levels of sustainability in their own region and set their own targets towards improving their sustainability levels.

In particular, measurement of sustainability practices using SEM in the three selected regions reveals some interesting results. Whereas SMEs in the Midlands are giving first priority to the economic and operational practices, Normandy and Eastern Indian SMEs are additionally focused on the environmental and social practices, respectively. Especially, the latter finding may be attributed to an inherent difference that emerge between a developing country such as India and a developed country such as the UK, where for the latter social practices are not considered as an issue to be solved since their implementations are often taken for granted.

As regards the measurement of sustainability performance at the regional level, it is seen once again that UK SMEs are more economic and operational focused. In Eastern India, on the other hand, SMEs give more emphasis on their operational and social aspects of their sustainability performance. The overall sustainability performance scores (Midlands, UK: 0.76; Normandy, France: 0.61; Eastern India: 0.51) are indicative of the inherent differences between developed and developing countries, and the difficulties of the latter to achieve sustainability levels comparable to that of developed countries.

Policy makers in each area can make use and benefit from these results, by providing them with an objective picture of their regional SMEs' sustainability performance, and notifying them of their strengths and weaknesses on certain aspects of sustainability. Thus, from the local policymaker perspective, the results of our analysis suggest that in order for the policymakers of Midlands, UK to improve the sustainability levels of SMEs in their region of interest, the focus should be more on the environmental and social aspects of sustainability practices and performance. Accordingly, policymakers of the Normandy region should focus more on providing regulatory and/or financial incentives for their regional SMEs to raise their levels on specific practice and performance sustainability indices, such as operational and social practices and social performance. Finally, the policymakers in Eastern India have to set their efforts towards specific operational and environmental practices, as well as to provide policy guidance towards ameliorating their regional SMEs' economic and environmental performance. 
Additionally, the calculated factor score weights of the performed SEM analysis provide a robust tool for individual SMEs to calculate their own individual overall sustainability index of practices and performance, as well as indices that concentrate on the separate constructs of economic, operational, environmental and social sustainability measures. In this way, a company can benchmark its sustainability performance and compare to the average performance levels of their region and also to be able to detect and improve specific shortcomings.

In overall, the results of our analysis using data from a diverse setting of various geographical locations, show that the SEM modeling is able to measure the level of sustainability practices and performances of SMEs in a particular region. The obtained results may be utilized by both individual SMEs and policy makers; firstly, the derived index measurements could provide SMEs' owners and managers with an assessment of their company as regards the current levels of sustainability practices and performance, and also provide a good guide for taking decisions for targeted improvements at specific parts of their supply chain sustainability process. Secondly, the outcome of this study may be also utilized by policy makers of a specific region, e.g., the city council, in the sense that they can make use of these results in order to benchmark their regional SMEs' performance. In this way, local policy makers can make targeted interventions in order to contribute to the enhancement of sustainability of SMEs at the local level. What is more important, our aggregated indices, calculated at the regional level, could be used as a basis for individual SMEs to compare with the average sustainability performance in their regional cluster of relative SMEs.

The proposed SMEs' sustainable supply chain performance measurement model doesn't establish objective causal relationship between each practice and performance criteria. It assumes that enhancing sustainability practices in line with the analysis results will enhance overall sustainability performance. These aspects could be considered for further research.

Acknowledgements The research leading to these results has received funding from the European Union's Horizon 2020 research and innovation programme under the Marie Sklodowska-Curie Grant Agreement No. 788692 .

Open Access This article is distributed under the terms of the Creative Commons Attribution 4.0 International License (http://creativecommons.org/licenses/by/4.0/), which permits unrestricted use, distribution, and reproduction in any medium, provided you give appropriate credit to the original author(s) and the source, provide a link to the Creative Commons license, and indicate if changes were made.

\section{Appendix}

See Tables 14, 15, 16 and 17 and Figs. 4, 5 and 6. 


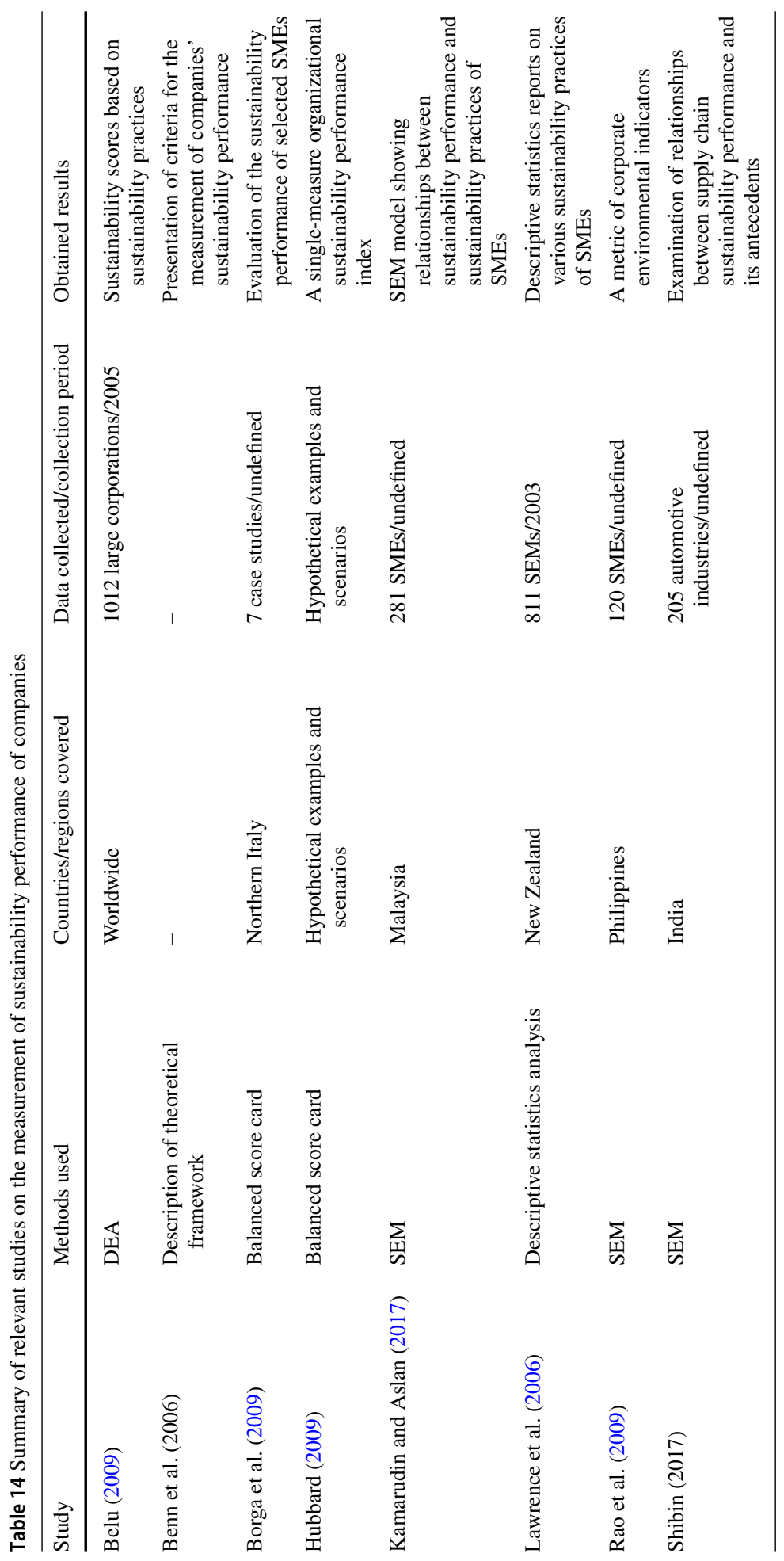


Table 15 Descriptive statistics for the observed items of the questionnaire (complete data)

\begin{tabular}{|c|c|c|c|c|}
\hline Items & Mean & $\mathrm{SD}$ & Min & $\operatorname{Max}$ \\
\hline ECO_PR_1 & 4.74 & 2.98 & 1 & 10 \\
\hline ECO_PR_2 & 2.87 & 1.74 & 1 & 8 \\
\hline OPR_PR_1 & 2.62 & 1.15 & 1 & 5 \\
\hline OPR_PR_2 & 2.22 & 1.11 & 1 & 5 \\
\hline OPR_PR_3 & 2.89 & 0.97 & 1 & 5 \\
\hline OPR_PR_4 & 2.42 & 1.43 & 1 & 5 \\
\hline ENV_PR_1 & 2.45 & 0.84 & 1 & 5 \\
\hline ENV_PR_2 & 2.30 & 1.18 & 1 & 5 \\
\hline ENV_PR_3 & 2.83 & 1.05 & 1 & 5 \\
\hline SOC_PR_1 & 2.30 & 1.22 & 1 & 4 \\
\hline SOC_PR_2 & 2.42 & 1.21 & 1 & 5 \\
\hline ECO_PER_1 & 3.80 & 2.59 & 1 & 10 \\
\hline ECO_PER_2 & 2.69 & 1.44 & 1 & 7 \\
\hline OPR_PER_1 & 3.76 & 1.62 & 1 & 7 \\
\hline OPR_PER_2 & 3.11 & 1.18 & 1 & 5 \\
\hline OPR_PER_3 & 2.86 & 1.23 & 1 & 5 \\
\hline OPR_PER_4 & 2.82 & 1.41 & 1 & 5 \\
\hline OPR_PER_5 & 3.18 & 1.03 & 1 & 5 \\
\hline OPR_PER_6 & 3.17 & 1.27 & 1 & 5 \\
\hline OPR_PER_7 & 2.94 & 0.93 & 1 & 5 \\
\hline OPR_PER_8 & 2.27 & 1.23 & 1 & 5 \\
\hline ENV_PER_1 & 2.99 & 1.26 & 1 & 5 \\
\hline ENV_PER_2 & 2.56 & 1.28 & 1 & 5 \\
\hline ENV_PER_3 & 2.87 & 1.01 & 1 & 5 \\
\hline SOC_PER_1 & 2.24 & 1.21 & 1 & 5 \\
\hline SOC_PER_2 & 2.90 & 1.06 & 1 & 5 \\
\hline
\end{tabular}


Table 16 Bibliographic sources for the selection of practices and performances indicators

\begin{tabular}{ll}
\hline Dimensions/indicators & Bibliographic references
\end{tabular}

Economic practices

Infrastructure

Patyal and Koilakuntla (2015)

Number of employees

Devins et al. (2004)

Economic performance

Turnover

Whyman and Petrescu (2015)

Business growth

Wolff and Pett (2006)

Operational practices

CRM Practices

Nguyen and Waring (2013)

SRM Practices

Pala et al. (2014)

Standardised business process

Patyal and Koilakuntla (2015)

Lean Practices

Hu et al. (2015)

Operational performance

Long term relationship with customers

Towers and Burnes (2008)

CRM effectiveness

Demand uncertainties

Nguyen and Waring (2013)

Long term relationship suppliers

Quah and Udin (2011)

SRM effectiveness

Wyld et al. (2012)

Supply uncertainties

Hoejmose et al. (2013)

Business process effectiveness

Koh and Simpson (2005)

Lean effectiveness

Lewis et al. (2006)

Environmental practices

Chay et al. (2015)

Adopting standardized environmental system

Waste management practices

Su-Yol (2008)

Energy consumption and emission control

Abdul-Rashid et al. (2017)

Environmental performance

Effectiveness of environmental system

Su-Yol (2008)

Waste reduction

Abdul-Rashid et al. (2017)

Reduction energy consumption and emissions

Social practices

CSR practices

Jamali et al. (2009)

Health and safety practices

Santos (2011)

Social performance

CSR performance

Tseng et al. (2010)

Health and safety performance

Groves et al. (2011) 


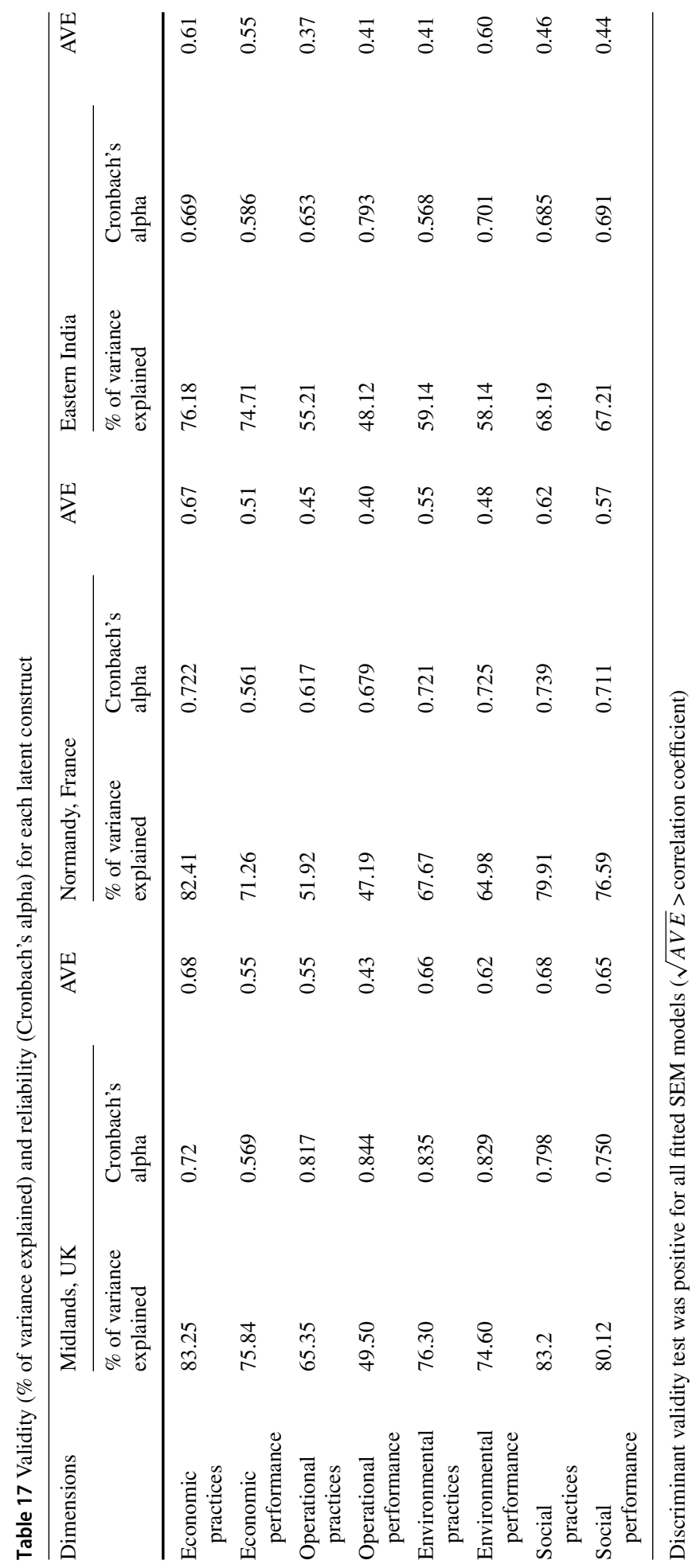



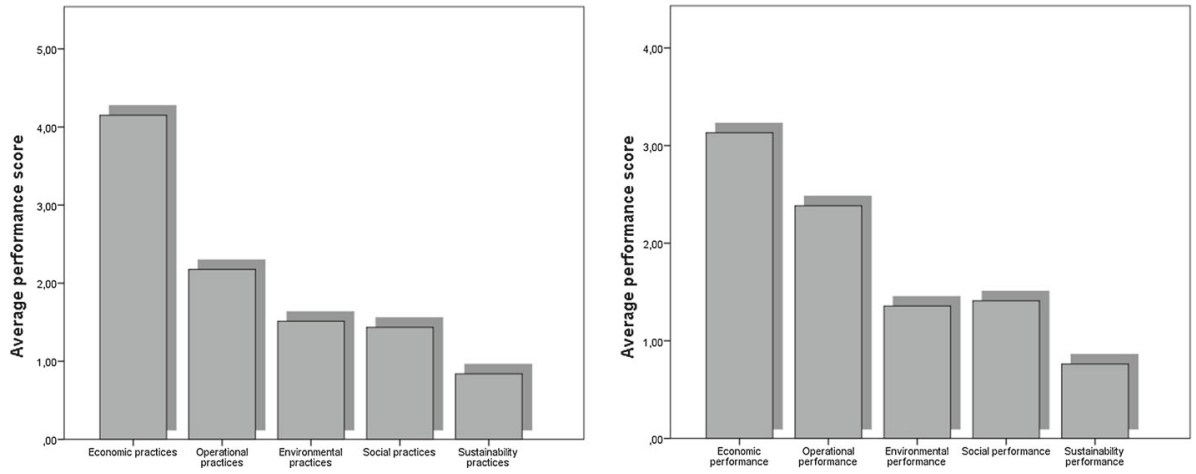

Fig. 4 Average sustainability index scores (Midlands, UK)
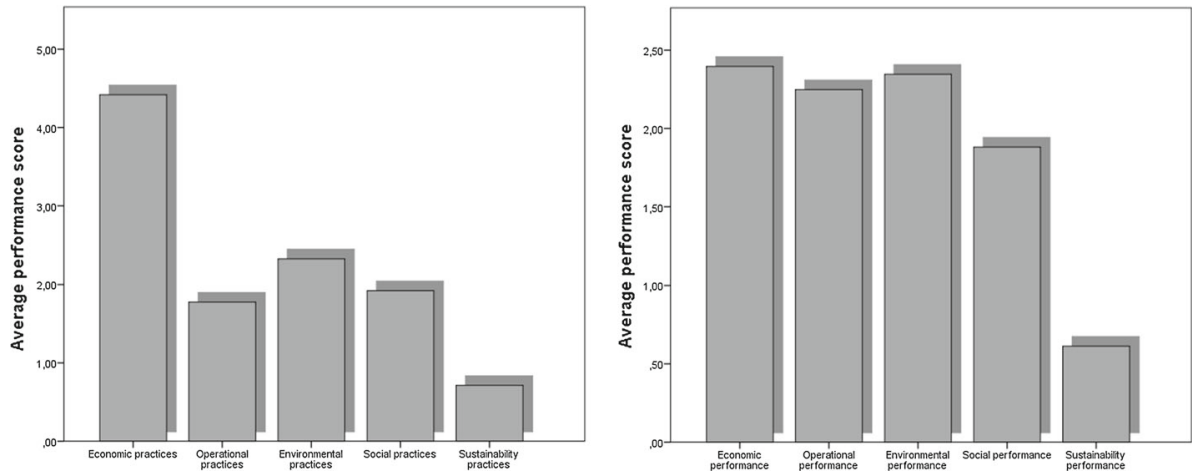

Fig. 5 Average sustainability index scores (Normandy, France)
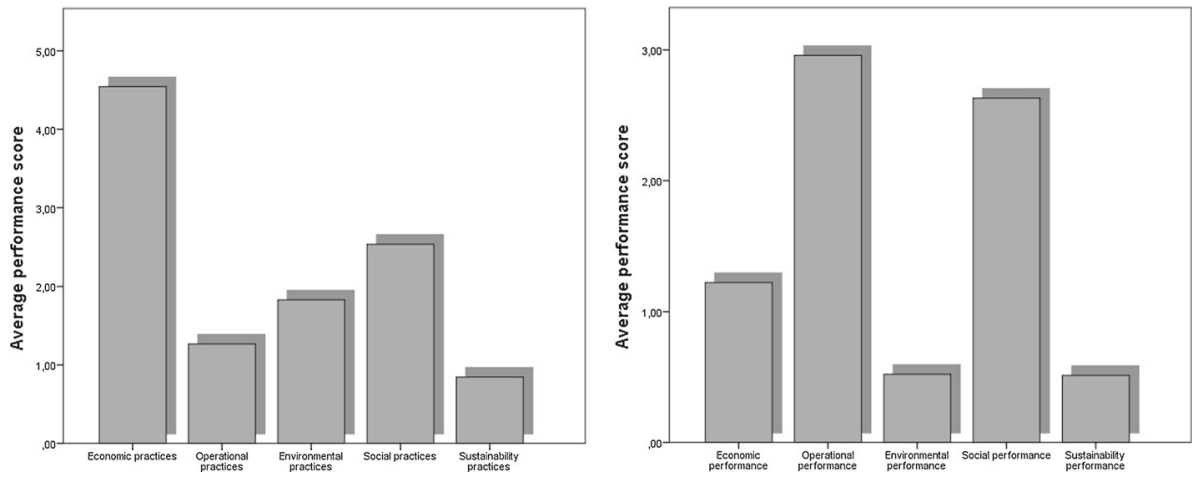

Fig. 6 Average sustainability index scores (Eastern India)

\section{References}

Abdul-Rashid, S. H., Sakundarini, N., Raja Ghazilla, R. A., \& Thurasamy, R. (2017). The impact of sustainable manufacturing practices on sustainability performance: Empirical evidence from Malaysia. International Journal of Operations \& Production Management, 37(2), 182-204.

Ahn, H. (2005). How to individualise your balanced scorecard. Measuring Business Excellence, 9(1), 5-12. 
Ammenberg, J., \& Hjelm, O. (2003). Tracing business and environmental effects of environmental management systems - A study of networking small and medium-sized enterprises using a joint environmental management system. Business Strategy and the Environment, 12(3), 163-174.

Arbuckle, J. L. (2014). Amos 23.0 user's guide. Chicago, IBM SPSS.

Barcus, A., \& Montibeller, G. (2008). Supporting the allocation of software development work in distributed teams with multi-criteria decision analysis. Omega, 36(3), 464-475.

Belu, C. (2009). Ranking corporations based on sustainable and socially responsible practices. A data envelopment analysis (DEA) approach. Sustainable Development, 17(4), 257-268.

Benn, S., Dunphy, D., \& Griffiths, A. (2007). Enabling change for corporate sustainability: An integrated perspective. Australasian Journal of Environmental Management, 13(3), 156-165.

Bhattacharya, A., Mohapatra, P., Kumar, V., Dey, P. K., Brady, M., \& Tiwari, M. K. (2014). Green supply chain performance measurement using fuzzy ANP-based balanced scorecard: a collaborative decision-making approach. Production Planning \& Control, 25(8), 698-714.

Bollen, K. A. (1989). Structural equations with latent variables. New York: Wiley.

Borga, F., Citterio, A., Noci, G., \& Pizzurno, E. (2009). Sustainability report in small enterprises: Case studies in Italian furniture companies. Business Strategy and the Environment, 18(3), 162-176.

Bryman, A., \& Cramer, D. (2005). Quantitative data analysis with SPSS12 and 13. A guide for social scientists. East Sussex: Routledge.

Castka, P., Balzarova, M. A., \& Bamber, C. J. (2004). How can SMEs effectively implement the CSR agenda? A UK case study perspective. Corporate Social Responsibility and Environment Management, 11(1), $140-149$.

Charnes, A., Cooper, W. W., \& Rhodes, E. L. (1978). Measuring the efficiency of decision making units. European Journal of Operational Research, 2, 429-444.

Chay, T., Xu, Y., Tiwari, A., \& Chay, F. (2015). Towards lean transformation: The analysis of lean implementation frameworks. Journal of Manufacturing Technology Management, 26(7), 1031-1052.

Chen, S.-C., \& Lee, A. H. I. (2010). Performance measurement of SMEs' employees by fuzzy multi-criteria decision theory. IEEE Xplore. https://doi.org/10.1109/3CA.2010.5533661.

Chen, Y., \& Zhu, J. (2004). Measuring information technology's indirect impact on firm performance. Information Technology and Management, 5(1-2), 9-22.

Chiu, Y.-H., Huang, C.-W., \& Ma, C.-M. (2011). Assessment of China transit and Economic efficiencies in a modified value-chains DEA model. European Journal of Operational Research, 209(2), 95-103.

Devins, D., Johnson, S., \& Sutherland, J. (2004). Employer characteristics and employee training outcomes in UK SMEs: A multivariate analysis. Journal of Small Business and Enterprise Development, 11(4), 449-457.

Easton, L., Murphy, D. J., \& Pearson, J. N. (2002). Purchasing performance evaluation: With data envelopment analysis. European Journal of Purchasing \& Supply Management, 8(3), 123-134.

Fornell, C., \& Larcker, D. F. (1981). Evaluating structural equation models with unobservable variables and measurement error. Journal of Marketing Research, 18(1), 39-50.

Garengo, P., Biazzo, S., \& Bititci, U. S. (2005). Performance measurement systems in SMEs: A review for a research agenda. International Journal Management Review, 7(1), 25-27.

Griethuijsen, R. A. L. F., Eijck, M. W., Haste, H., Brok, P. J., Skinner, N. C., Mansour, N., et al. (2014). Global patterns in students' views of science and interest in science. Research in Science Education, 45(4), 581-603.

Groves, C., Frater, L., Lee, R., \& Stokes, E. (2011). Is There room at the bottom for CSR? Corporate social responsibility and nanotechnology in the UK. Journal of Business Ethics, 101(4), 525-552.

Hair, J., Black, W., Babin, B., Anderson, R., \& Tatham, R. (2006). Multivariate data analysis (6th ed.). Uppersaddle River, NJ: Pearson Prentice Hall.

Halkos, G. E., \& Salamouris, D. S. (2004). Efficiency measurement of the Greek commercial banks with the use of financial ratios: A data envelope analysis approach. Management Accounting Research, 15(2), 201-224.

Hart, S. L., \& Milstein, M. B. (2003). Creating sustainable value. Academy of Management Executive, 17(2), 56-69.

Heene, M., Hilbert, S., Draxler, C., Ziegler, M., \& Bühner, M. (2011). Masking misfit in confirmatory factor analysis by increasing unique variances: A cautionary note on the usefulness of cutoff values of fit indices. Psychological Methods, 16(3), 319-336.

Hoejmose, S., Brammer, S., \& Millington, A. (2013). An empirical examination of the relationship between business strategy and socially responsible supply chain management. International Journal of Operations \& Production Management, 33(5), 589-621.

Hoque, Z. (2014). 20 years of studies on the balanced scorecard: Trends, accomplishments, gaps and opportunities for future research. The British Accounting Review, 46(1), 33-59. 
Hu, L. T., \& Bentler, P. M. (1999). Cutoff criteria for fit indexes in covariance structure analysis: Conventional criteria versus new alternatives. Structural Equation Modeling, 6(1), 1-55.

Hu, Q., Mason, R., Williams, S. J., \& Found, P. (2015). Lean implementation within SMEs: A literature review. Journal of Manufacturing Technology Management, 26(7), 980-1012.

Hubbard, G. (2009). Measuring organizational performance: Beyond the triple bottom line. Business Strategy and the Environment, 18, 177-191.

Hudson, M., Smart, A., \& Bourne, M. (2001). Theory and practice in SME performance measurement systems. International Journal of Operations \& Production Management, 21(8), 1096-1115.

Iacobucci, D. (2010). Structural equations modeling: Fit indices, sample size, and advanced topics. Journal of Consumer Psychology, 20, 90-98.

Jamali, D., Zanhour, M., \& Keshishian, T. (2009). Peculiar strengths and relational attributes of SMEs in the context of CSR. Journal of Business Ethics, 87(3), 355-377.

Johnson, M. P., \& Schaltegger, S. (2016). Two decades of sustainability management tools for SMEs: How far have we come? Journal of Small Business Management, 54(2), 481-505.

Jöreskog, K. G. (1970). A general method for analysis of covariance structures. Biometrika, 57, $239-251$.

Kamarudin, A. B., \& Aslan, A. S. (2017). Modelling sustainable performance of SME through green management implementation in the new economic transition. Proceeding of Mechanical Engineering Research, 2017, 219-221.

Kaplan, R. S., \& Norton, D. P. (1992). The balanced scorecard-Measures that drive performance. Harvard Business Review, 70(1/2), 71-79.

Koh, S. C. L., \& Simpson, M. (2005). Change and uncertainty in SME manufacturing environments using ERP. Journal of Manufacturing Technology Management, 16(5/6), 629-653.

Lawrence, S. R., Collins, E., Pavlovich, K., \& Arunachalam, M. (2006). Sustainability practices of SMEs: The case of NZ. Business Strategy and the Environment, 15(4), 242-257.

Lewis, W. G., Pun, K. F., \& Lalla, T. R. M. (2006). Empirical investigation of the hard and soft criteria of TQM in ISO 9001 certified small and medium-sized enterprises. The International Journal of Quality \& Reliability Management, 23(8), 964-985.

Libby, T., Salterio, S. E., \& Webb, A. (2004). The balanced scorecard: The effects of assurance and process accountability on managerial judgment. Accounting Review, 79(4), 1075-1094.

Marques, G., Gourc, D., \& Lauras, M. (2010). Multi-criteria performance analysis for decision making in project management. International Journal of Project Management, 29, 1057-1069.

Marsh, H. W., Hau, K.-T., \& Wen, Z. (2004). In search of golden rules: Comment on hypothesis-testing approaches to setting cutoff values for fit indexes and dangers in overgeneralizing Hu and Bentler's (1999) findings. Structural Equation Modeling, 11(3), 320-341.

Masurel, E. (2007). Why SMEs invest in environmental measures: Sustainability evidence from small and medium-sized printing firms. Business Strategy and the Environment, 16(3), 190-201.

Nejati, M., Quazi, A., Amran, A., \& Ahmad, N. H. (2016). Social responsibility and performance: Does strategic orientation matter for small businesses? Journal of Small Business Management. https://doi.or g/10.1111/jsbm.12305.

Nguyen, T. H., \& Waring, T. S. (2013). The adoption of customer relationship management (CRM) technology in SMEs: An empirical study. Journal of Small Business and Enterprise Development, 20(4), 824-848.

Nørreklit, H. (2000). The balance on the balanced scorecard-A critical analysis of some of its assumptions. Management Accounting Research, 11(1), 65-88.

Pala, M., Edum-Fotwe, F., Ruikar, K., Doughty, N., \& Peters, C. (2014). Contractor practices for managing extended supply chain tiers. Supply Chain Management, 19(1), 31-45.

Patyal, V. S., \& Koilakuntla, M. (2015). Infrastructure and core quality practices in Indian manufacturing organizations: Scale development and validation. Journal of Advances in Management Research, 12(2), $141-175$.

Petts, J. (2000). The regulator-regulated relationship and environmental protection: Perceptions in small and medium sized enterprises. Environment and Planning, 18(3), 191-192.

Petts, J., Herd, A., \& O’hecocha, M. (1998). Environmental responsiveness, individuals and organizational learning: SME experience. Journal of Environmental Planning and Management, 41(6), 711-731.

Prabawani, P. (2013). Measuring SMEs' sustainability: A literature review and agenda for research. International Journal of Management and Sustainability, 2(12), 193-207.

Quah, H. S., \& Udin, Z. M. (2011). Supply chain management from the perspective of value chain flexibility: An exploratory study. Journal of Manufacturing Technology Management, 22(4), 506-526.

Rao, P., Singh, A., La O'Castillo, O., Intal, P., Jr., \& Sajid, A. (2009). A metric for corporate environmental indicators ... For small and medium enterprises in the Philippines. Business Strategy and the Environment, $18(1), 14-31$. 
Roxas, B., Ashill, N., \& Chadee, D. (2016). Effects of entrepreneurial and environmental sustainability orientations on firm performance: A study of small businesses in the Philippines. Journal of Small Business Management. https://doi.org/10.1111/jsbm.12259.

Saad, M., Kumar, V., \& Bradford, J. (2017). An investigation into the development of the absorptive capacity of manufacturing SMEs. International Journal of Production Research, 55(23), 6916-6931.

Santos, M. (2011). CSR in SMEs: Strategies, practices, motivations and obstacles. Social Responsibility Journal, 7(3), 490-508.

Saranga, H., \& Moser, R. (2010). Performance evaluation of purchasing and supply management using value chain DEA approach. European Journal of Operational Research, 207(1), 197-205.

Shewell, P., \& Migiro, S. (2016). Data envelopment analysis in performance measurement: A critical analysis of the literature. Problems and Perspectives in Management, 14(3), 705-713.

Shibin, K.T., Dubey, R., Gunasekaran, A., Hazen, B., Roubaud, D., Gupta, S., \& Foropon, C. (2017). Examining sustainable supply chain management of SMEs using resource based view and institutional theory. Annals of Operations Research, 1-26.

Simpson, M., Taylor, N., \& Barker, K. (2004). Environmental responsibility in SMEs: Does it deliver competitive advantage? Business Strategy and the Environment, 13(3), 156-171.

Soheilirad, S., Govindan, K., Mardani, A., Zavadskas, E.K., Nilashi, M., \& Zakuan, N. (2017). Application of data envelopment analysis models in supply chain management: A systematic review and meta-analysis. Annals of Operations Research, 1-55.

Su-Yol, L. (2008). Drivers for the participation of small and medium-sized suppliers in green supply chain initiatives. Supply Chain Management, 13(3), 185-198.

SPSS Inc. (1999). SPSS Base 10.0 for Windows User's Guide. SPSS Inc., Chicago, IL.

Towers, N., \& Burnes, B. (2008). A composite framework of supply chain management and enterprise planning for small and medium-sized manufacturing enterprises. Supply Chain Management, 13(5), 349-355.

Tseng, Y. F., Yen-Chun, J. W., Wu, W.-H., \& Chun-Yu, C. (2010). Exploring corporate social responsibility education: The small and medium-sized enterprise viewpoint. Management Decision, 48(10), 1514-1528.

Wang, C. H., Gopal, R. D., \& Zionts, S. (1997). Use of data envelopment analysis in assessing information technology impact on firm performance. Annals of Operations Research, 73, 191-213.

Whyman, P. B., \& Petrescu, A. I. (2015). Workplace flexibility practices in SMEs: Relationship with performance via redundancies, absenteeism, and financial turnover. Journal of Small Business Management, 53(4), 1097.

Williamson, D., \& Lynch-Wood, G. (2006). Drivers of environmental behaviour in manufacturing SMEs and implications for CSR. Journal of Business Ethics, 6(3), 317-330.

Wolff, J. A., \& Pett, T. L. (2006). Small-firm performance: Modeling the role of product and process improvements. Journal of Small Business Management, 44(2), 268-284.

Wong, W.-P., \& Wong, K.-Y. (2007). Supply chain performance measurement system using DEA modeling. Industrial Management \& Data Systems, 107(3), 361-381.

Wyld, J., Pugh, G., \& Tyrrall, D. (2012). Can powerful buyers "exploit" SME suppliers? Journal of Small Business and Enterprise Development, 19(2), 322-334.

Zhai, Y. M., Sun, W. Q., Tsai, S. B., Wang, Z., Zhao, Y., \& Chen, Q. (2018). An empirical study on entrepreneurial orientation, absorptive capacity, and SMEs' innovation performance: A sustainable perspective. Sustainability, 10(2), 314. 